\title{
Sustentabilidad y Democratización de las Sociedades Rurales de América Latina ${ }^{1}$
}

DIEGO PIÑEIRO*

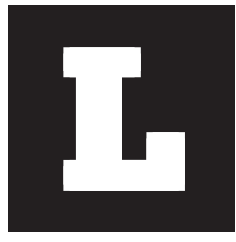

a ALASRU es una organización que reúne a todos los que trabajan en la subdisciplina de la Sociología Rural en América Latina con el fin de estimular la difusión y el perfeccionamiento de la misma, promover su adopción en las instituciones de enseñanza, promover la investigación, facilitar la publicación de investigaciones originales, y difundir, mantener informados y servir de enlace a todos los profesionales del continente.

Habiendo sido creada en la ciudad de Buenos Aires en 1969, con lo cual tenemos ya 33 años de existencia, afiliados a la Asociación Internacional de Sociología Rural, la ALASRU es una institución profesional y científica, consolidada y reconocida en todo el mundo.

Como lo hacemos cada cuatro años, hoy nos encontramos reunidos nuevamente para iniciar las deliberaciones de nuestro VI Congreso.

Organizar un Congreso de estas características es una ímproba tarea y mas aún en las difíciles circunstancias económicas en que se encuentran muchos de los países del continente, que ha obligado a recortar los gastos estatales, disminuyendo, como suele ocurrir, el financiamiento de la investigación científica. Como ya lo ha hecho notar la Prof. Brumer muchas

1 Discurso inaugural del VI Congreso de la Asociación Latinoamericana de Sociología Rural.

* Presidente de la ALASRU en el periodo de 1998-2002. 
son las organizaciones que han colaborado de distintas maneras para realizar este evento. Vaya a ellas nuestro agradecimiento. De mi parte quiero agradecer una vez mas a la Universidad Federal de Rio Grande do Sul, por su gesto generoso de albergar y apoyar nuestro Congreso. También quiero agradecer al Comité Académico y muy especialmente a la Comisión Organizadora de este Congreso eficientemente liderada por la Profesora Anita Brumer, quien, nos consta, ha dejado lo mejor de sí para que hoy podamos estar todos aquí reunidos.

Este VI Congreso delibera bajo la Convocatoria "Sustentabilidad y Democratización de las Sociedades Rurales de América Latina". Permítanme extenderme en las razones por las cuales elegimos este tema.

Las décadas del 70 y del 80 fueron muy penosas para América Latina. En muchos de nuestros países se instauraron gobiernos dictatoriales que suprimieron las libertades individuales y los derechos políticas y adoptaron modelos económicos que solo aumentaron la penuria de los pueblos. A la década del 80 se la conoce como la "década perdida" para el Desarrollo. Hacia mediados de la misma, agotados los procesos que dieron lugar a las dictaduras, gradualmente se retorna a los gobiernos constitucionales. Un soplo de alegría y de esperanza recorrió el continente. Se esperaban años de crecimiento económico pero también de desarrollo y redistribución de los beneficios del mismo.

Pero los programas de ajuste estructural, desregulación estatal, privatización, apertura de la economía a las inversiones extranjeras y la apertura de las fronteras comerciales que han seguido disciplinadamente los gobiernos latinoamericanos, no trajeron mas bienestar a la población sino por el contrario mayor pobreza, desigualdades sociales e inequidad. Por otro lado la deuda externa del continente creció a niveles asfixiantes impidiendo la capitalización y el desarrollo económico.

¿Qué es lo que está ocurriendo en el ámbito de las sociedades rurales de nuestro continente? 
En primer lugar quisiera remarcar que cualquier referencia a ellas debe hacerse en el marco de las grandes transformaciones que están ocurriendo a nivel científico en el campo de la biología y de la informática que son los que dominarán los procesos agrícolas hacia el futuro.

Las grandes compañías trasnacionales aliadas con los laboratorios donde se investiga para desentrañar las claves de la vida, dominan cada vez mas firmemente el campo de las biotecnologías, de los insumos para la agricultura y de los sistemas agroalimentarios. En cada uno de nuestros países los complejos agroindustriales controlan la producción agrícola exportable, vinculando a ellos a los productores empresariales: han sido pocos los campesinos y productores familiares que han podido insertarse en ellos y beneficiarse con el cambio tecnológico y el acceso a mercados que conlleva esta inserción.

Mas bien se está hoy en presencia de una agricultura a dos velocidades: una agricultura con fuerte utilización de insumos químicos, mecánicos y biotecnológicos, vinculada a los complejos agroindustriales, cuyos agentes son empresarios agrarios y cuyo destino principal es la exportación. Y una agricultura donde predominan campesinos y productores familiares con menor desarrollo tecnológico volcada a un mercado interno que es menos dinámico, por la propia situación de pobreza de las grandes masas de trabajadores/consumidores urbanos y rurales.

En este contexto internacional y como consecuencia de la valorización de las tierras productivas, la concentración de la tierra ha aumentado a pesar de que algunos gobiernos han emprendido tímidos programas de colonización o reforma agraria: es que simplemente la velocidad con que los campesinos, productores familiares y aún medianos propietarios se ven expulsados de la tierra como consecuencia de los cambios tecnológicos y de este modelo agroexportador, es aún mayor que estos esfuerzos.

Los empleos rurales han decrecido mientras, en cambio, aumentan los trabajadores que teniendo residencia rural se emplean en los servicios 
o en otras ramas de la economía. Si en otras épocas de la historia, la liberación de fuerza de trabajo del campo para contar con brazos para el desarrollo industrial era un efecto buscado, hoy los que no encuentran trabajo en el campo migran a la ciudades solo para aumentar los índices de desocupación, ya que la industria y los servicios también están pasando por un intenso proceso de cambio tecnológico que reduce la cantidad de puestos de trabajo.

Aparecen entonces nuevas formas de combinar lo rural con lo urbano. Productores familiares que amplían y estabilizan sus ingresos trabajando parte del tiempo fuera de su parcela, en una modalidad que se ha denominado "pluriactividad". Población campesina migrante que se asienta transitoriamente en los suburbios de pueblos y ciudades, que no pierde contacto con su localidad y su familia de origen, trasegando mano de obra, dinero, bienes y alimentos de una a otra residencia; pequeños pueblos que son asiento de trabajadores rurales zafrales; pobladores rurales próximos a ciudades que trabajan en ellas residiendo con su familia en su parcela rural: en fin, las mil y una formas con que el ingenio popular encuentra formas de resistir el desempleo y la falta de oportunidades en el campo.

A ello hay que agregarle los grandes movimientos de población principalmente motivados por la búsqueda de empleo. Así los trabajadores se mueven dentro de los países desde regiones mas pobres hacia aquellas que tienen una agricultura mas intensiva que precisa de la mano de obra zafral para levantar las cosechas. O también se movilizan de un país a otro, frecuentemente estimulados no solo por la existencia de empleo sino también por las diferencias de valor de la moneda. En algunos países los movimientos de población han sido impulsados por la violencia programada de la construcción de grandes represas hidroeléctricas que desplazan la población que habita en sus áreas de inundación. También, lamentablemente, en algunos de nuestros países hay población campesina desplazada por la violencia política.

En materia de cambio tecnológico, la agricultura de nuestro continen- 
Sociologias, Porto Alegre, ano 5, no 10, jul/dez 2003, p. 26-34

te a tomado acríticamente el modelo de la Revolución Verde, que combina los avances biológicos, con la utilización de diversos agroquímicos que son los que permiten expresar el mayor potencial genético de las semillas, utilizando maquinarias cada vez mas sofisticadas. Esto ha provocado indudables incrementos en los rendimientos de la agricultura empresarial, pero son muy pocos los productores familiares y campesinos que pueden acceder a estas tecnologías. Nuestros institutos de investigación y de extensión rural, en concordancia con las políticas agrícolas implementadas desde el Estado, han preferido volcar sus esfuerzos a adaptar esta tecnología a las condiciones de los empresarios agrícolas que producen para la exportación, antes que dedicarse a crear una tecnología propia y apropiada para la gran mayoría de pequeños productores.

El cambio técnico ha reducido notablemente la demanda de mano de obra. Los desempleados del campo se suman a los desocupados de las ciudades conduciendo al nuevo fenómeno de la exclusión. Existe hoy tanto en el campo como en la ciudad un contingente demasiado numeroso de trabajadores que no se precisan, que no consiguen ni conseguirán empleo, que para el sistema económico dominante simplemente están de mas. Son, parafraseando a Robert Castel, los nuevos "inútiles para el mundo". La exclusión debe verse como un fenómeno complejo que consiste no solo en la falta de inserción laboral sino también en la pérdida de otras ligazones con el sistema social como el acceso a la educación, al cuidado de la salud, a la vivienda, etc. que configuran el derecho a la ciudadanía.

También la agricultura empresarial se enfrenta a dificultades. La apertura comercial ha provocado una fuerte competencia entre los empresarios agrícolas de los distintos países de América Latina por la colocación de sus productos en los mercados de alto poder adquisitivo de los países mas industrializados. Más aún la ausencia de barreras comerciales que antes definían el espacio económico del Estado-Nación, hace que las crisis frecuentes en los mercados agrícolas internacionales repercutan sin 
mediaciones en los empresarios rurales del continente. Mientras crece el endeudamiento estos quedan así presos del sistema financiero, socio ahora irreductible, de la empresa agrícola. Estamos asistiendo a una lucha entre el capital productivo y el capital financiero, que ha llevado en varios de nuestros países, a presenciar insospechadas alianzas entre productores familiares y empresarios agrícolas, en protestas públicas contra la expoliación a que los somete el sistema Bancario.

La respuesta mas frecuente a la crisis agrícola ha sido una mayor presión sobre los Recursos Naturales: los gobiernos se empeñan por liberar a la producción las pocas tierras aún inexplotadas con el fin de obtener mas ingresos para pagar la deuda externa. Los empresarios deforestan impunemente, labran nuevas tierras, incrementan el uso de insumos químicos, extienden las áreas de riego, apelan al uso de semillas transgénicas con el fin de bajar sus costos y aumentar la productividad. Los campesinos confinados en sus pequeñas parcelas, apenas defendiendo la tierra que poseen, aumentan la velocidad de rotación de los cultivos sin hacer los barbechos necesarios, deforestan, sobrepastorean las tierras comunales, presionan indebidamente sobre los recursos pesqueros en busca de sustento y sobre los recursos forestales en busca de leña. El deterioro de los Recursos Naturales es tal vez uno de los aspectos mas preocupantes de la evolución del campo latinoamericano en las últimas dos décadas.

Pero también debemos reconocer que durante la última década del siglo XX hemos visto resurgir a las organizaciones y movimientos sociales en el campo latinoamericano. Estas habían sido debilitadas y desmanteladas durante las décadas del 70 y del 80 bajo gobiernos autoritarios. Pero los campesinos, los pobladores de los barrios populares, los trabajadores rurales, los pequeños productores, tozudamente volvieron a juntarse en organizaciones locales, en comisiones de apoyo a la policlínica, en merenderos, en comisiones vecinales, en grupos religiosos, en cooperadoras escolares, en organizaciones gremiales, solo para citar algunos ejemplos. 
Sociologias, Porto Alegre, ano 5, no 10, jul/dez 2003, p. 26-34

Pero no solo ellos también las mujeres comienzan a organizarse a veces con motivos iniciales inmediatos dirigidos a solucionar los problemas de reproducción social de las unidades domésticas, pero gradualmente evolucionando hacia reclamos de género. La cuestión étnica resurge con fuerza y renovadas perspectivas. La indianidad es retomada por los pueblos indígenas que antes se organizaban como campesinos o como trabajadores, pero que hoy se organizan y reivindican lo que son: pueblos originarios con derecho a vivir como tales en naciones que deben reconocerse como pluriétnicas. Por otro lado los cambios que se conocen como "la nueva ruralidad" también han permitido quebrar la compartimentación de la organización popular urbana con la organización popular rural. Hoy con frecuencia, vemos que las manifestaciones de resistencia y rebeldía popular convocan codo a codo al trabajador informal urbano, a los desocupados de la ciudad y del campo, con los trabajadores rurales, los campesinos y los "sin tierra".

En la década del 90 hemos visto crecer muchos de estos procesos de acción colectiva para transformarse en organizaciones y movimientos de carácter nacional que con una nueva concepción mediática han saltado a la escena pública y han conseguido convertirse en obligados interlocutores del sistema político.

En días recientes, en este país que hoy nos hospeda, un partido político con una inmensa base popular ha ganado las elecciones nacionales. Es posible que en los próximos años algunos otros países de América Latina se sumen a este camino. Las democracias latinoamericanas se vigorizan con estos resultados. Son los derechos constitucionales que celosamente debemos preservar, los que han permitido lograr estos cambios. Nuevas esperanzas de cambios a favor de los desprotegidos corren por el continente. Pensamos que para que estos u otros gobiernos puedan implementar los cambios, es necesario que las organizaciones y movimientos del campo continúen con su labor de apoyo a las transformaciones reclamadas. 
Una democracia plena solo será posible con un nuevo enfoque del desarrollo. Un desarrollo que sea sustentable en el tiempo. Un desarrollo que no solo busque el crecimiento económico sino también la justicia distributiva y el pleno empleo. Que impulse la búsqueda de la equidad en el disfrute de los beneficios del desarrollo permitiendo un acceso igualitario a los derechos ciudadanos con una amplia participación popular en los distintos niveles de la sociedad. Y el convencimiento de que todo esto tendrá sentido si además se salvaguardan para las generaciones futuras los Recursos Naturales, sustento material insustituible de todo bienestar.

Como en los Congresos anteriores la Asociación Latinoamericana de Sociología Rural nos ha convocado para analizar estos y otros temas que serán expuestos, discutidos, debatidos por todos nosotros en los distintos paneles y mesas en que participaremos. Sepamos escuchar. Hagámoslo con honestidad intelectual, buscando la luz en la confrontación de ideas. Con espíritu científico, pero con pasión, porque sin ella, la razón poco vale.

Señoras, Señores, como Presidente de la ALASRU, les agradezco vuestra presencia y los invito a las deliberaciones.

Muchas gracias.

Diego E. Piñeiro

Presidente de ALASRU 
Sociologias, Porto Alegre, ano 5, no 10, jul/dez 2003, p. 26-34

\section{Resumen}

Al inaugurar las deliberaciones del VI Congreso de Sociología Rural su Presidente realiza un repaso de las principales temáticas que requieren de la atención de aquellos que se dedican a esta disciplina. En el marco de las grandes transformaciones que se avecinan signadas por la biotecnologia y la informática, y reconociendo sus aportes, se hace referencia a la existencia de una agricultura "a dos velocidades" y a la extensión del fenómeno de la exclusión económica y ciudadana. Se pasa revista a las distintas problemáticas que recorren a las sociedades rurales y se destaca el resurgimiento de organizaciones y movimientos sociales en el agro como un complemento valioso para el fortalecimiento de las democracias en la región.

Palabras-clave: VI Congreso de Sociología Rural, sustentabilidad, democratización, sociedades rurales, América Latina. 